\title{
Supportive release techniques provide no reintroduction benefit when efficacy and uptake is low
}

\author{
Hannah L. Bannister, Robert Branden, Steven Delean \\ David C. Paton and Katherine E. Moseby
}

\begin{abstract}
Release methods can influence the outcome of reintroductions. We tested the effect of delayed, immediate and supplementary food/shelter release treatments on the reintroduction of brushtail possums Trichosurus vulpecula to an environment in which introduced predators, particularly foxes, were subject to control. Monitoring of 48 radiocollared possums over 3 months revealed that immediate release possums settled into a stable range significantly faster than other groups, but there were no differences in survival, dispersal distance, reproduction or body condition. Ten days after release possums from all treatment groups had lost body mass, but by day 60 most were heavier than at the time of translocation. After release, possums sometimes used shelter sites easily accessible to predators, but within 3 weeks they regularly selected safer shelter. Risky shelter selection and loss of condition immediately after release suggests that supplementary food and shelter could be beneficial, but supportive measures were rarely used or did not have the desired effect. In an environment with higher predator densities, risky shelter selection could lead to high post-release predation, and mass loss could encourage animals to forage in riskier ways, further increasing vulnerability. In these environments effective uptake of supplementary food and shelter could reduce predation risk, but supplementary measures would need to be presented in a way that maximises uptake. In contrast, if post-release predation risk is low then supportive measures may not be required. Innovative methods for providing post-release support should continue to be developed for reintroductions to areas where supportive measures are needed.
\end{abstract}

Keywords Australia, brushtail possum, reintroduction, release method, supplementary feeding, translocation, Trichosurus vulpecula

\footnotetext{
Hannah L. Bannister (Corresponding author), Steven Delean and David C. PAton The University of Adelaide, School of Biological Sciences, North Terrace, Adelaide, South Australia 5005, Australia

E-mail hannah.bannister@adelaide.edu.au

Robert Brandle Department of Environment, Water and Natural Resources, Port Augusta, South Australia, Australia

Katherine E. Mosebi* University of New South Wales, School of Biological, Earth and Environmental Sciences, Sydney, New South Wales, Australia

${ }^{*}$ Also at: Ecological Horizons Pty Ltd, Kimba, South Australia, Australia

Received 6 August 2017. Revision requested 24 October 2017.

Accepted 21 November 2017. First published online 21 May 2018.
}

Supplementary material for this article is available at https://doi.org/10.1017/Soo30605317001843

\section{Introduction}

eintroductions are increasingly used as a tool to reverse R the decline of threatened species. The method of release has the potential to influence a reintroduction outcome. Post-release supportive measures often include temporary confinement (delayed release), protection from predators and/or the provision of supplementary food or shelter. Delayed releases theoretically enable animals to acclimatize to a new environment before having to locate their own food and shelter (Scott \& Carpenter, 1987) and, for some species, have been associated with smaller dispersal distances and higher survival compared to immediately released animals (Bright \& Morris, 1994; Mitchell et al., 2011; Knox \& Monks, 2014). Small dispersal distances aid in retaining animals within an area where other factors, such as introduced predators, may be more effectively controlled (Rickett et al., 2013). Some studies, however, report no differences between the survival or dispersal of delayed and immediate release animals (Hardman \& Moro, 2006), or found lower reintroduction success with delayed rather than immediate releases (Thompson et al., 2001; Richardson et al., 2015). The source of animals for translocation (wild vs captive-bred) may influence the effectiveness or necessity for alternative release methods (Fischer \& Lindenmayer, 2000; Moseby et al., 2014). Many studies reporting the outcome of delayed release methods have no control treatment (e.g. Pietsch, 1995; Poole \& Lawton, 2009). Furthermore, the provision of supportive measures is often assumed to result in uptake, but is not often monitored. Delayed releases have intuitive appeal but sometimes offer little benefit. Using reintroductions as experiments is essential to advance the science of reintroduction biology (Seddon et al., 2007; Swaisgood, 2010).

The brushtail possum Trichosurus vulpecula (hereafter possum) is a medium-sized (1-4 kg, Kerle et al., 1991), predominantly arboreal mammal once widespread throughout most of Australia, but now present in $<50 \%$ of its historic range (Kerle et al., 1992; Kerle, 2001). The species' decline is thought to be a result of a combination of factors, including predation by introduced predators (red foxes Vulpes vulpes, 
feral cats Felis catus and dingoes Canis lupus dingo), habitat alteration, the impacts of introduced herbivores, hunting, disease and drought (Kerle et al., 1992). In locations where foxes have been successfully controlled, remnant possum populations have increased (How \& Hillcox, 2000; Burrows \& Christensen, 2002). We used a trial reintroduction of the species in southern Australia to test the effect of post-release support on reintroduction outcomes.

Several possum translocations have been undertaken previously, but they have rarely been used to advance reintroduction protocols for the species and the outcomes were often unknown or unsuccessful (Supplementary Table 1). Furthermore, only nine of $21(43 \%)$ reported possum translocations included post-release monitoring of any kind, and only six of those monitored post-release dispersal. Hyperdispersal (long distance movement away from release sites) was reported on all occasions for possums undergoing both immediate and delayed release, when dispersal was monitored. With predation a major contributor to failed possum translocations (Pietsch, 1995; DEC, 2012), retaining released animals at a predator-controlled release site may improve reintroduction success. An effective delayed release method could therefore be useful for translocated possums. The non-research driven approaches of most previous possum translocations are evident, and few attempts have been made to rigorously test methods to improve post-release survival or limit dispersal, despite both having been problematic. In addition, no experimental comparisons have been made of delayed and immediate release methods for possums.

In the Ikara-Flinders Ranges National Park, foxes have been subject to intensive control since 1993 (Natural Resources SA Arid Lands, 2012), and because of this the reintroduction of possums was considered feasible. Expected low predation risk at our unfenced release site, combined with the relatively solitary, sedentary behaviour of possums suggests that an immediate release with supplementary food and shelter would be most effective (Moseby et al., 2014). Hyperdispersal has been identified as a problem previously, however (Supplementary Table 1). Based on this, we tested the influence of various combinations of supplementary food, shelter and temporary containment on the post-release survival, movement, reproduction, and change in body mass of possums reintroduced to the National Park.

\section{Study area}

Brushtail possums were sourced from the $11 \mathrm{~km}^{2}$ fenced, introduced predator-free section of Yookamurra Wildlife Sanctuary (Fig. 1), a conservation reserve run by the not-for-profit organization Australian Wildlife Conservancy. Mean annual rainfall is $339 \mathrm{~mm}$ (Station 24581, Bureau of Meteorology, 2017) and the

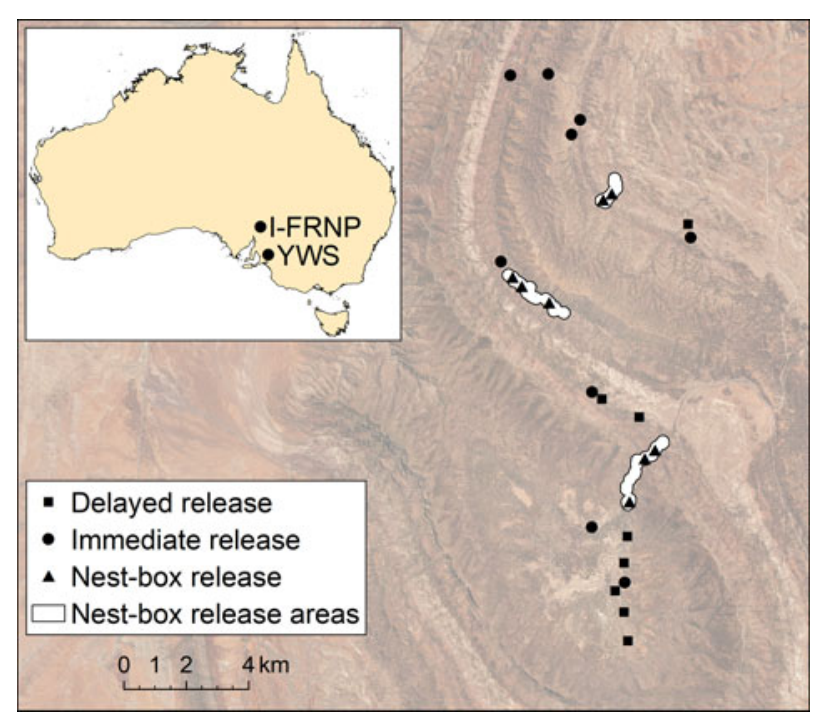

FIg. 1 The source (YWS, Yookamurra Wildlife Sanctuary) and release locations (I-FRNP, Ikara-Flinders Ranges National Park) for translocated radio-collared brushtail possums Trichosurus vulpecula within Australia (inset) and, the spatial arrangement of release sites within the Park.

vegetation is predominantly old growth mallee (Eucalyptus spp.). Possums were reintroduced to the $934 \mathrm{~km}^{2}$ IkaraFlinders Ranges National Park, c. 400 km north-north-west of the source population (Fig. 1), where they became regionally extinct in the 1940s (Tunbridge, 1991). Several habitat types are found in the Park, including Eucalyptus camaldulensis dominated creeklines, open eucalypt (E. camaldulensis/E. intertexta) and/or Callitris glaucophylla woodlands, mallee (Eucalyptus spp.) and mixed species (woodland/ shrubland) rocky slopes or creeklines. Vegetation condition was good, with known favoured food plants available (Eucalyptus spp., Acacia spp., mistletoe (Loranthaceae family) and other species (Kerle, 1984)). Tree hollows are the most common form of diurnal shelter for possums (How \& Hillcox, 2000; Isaac et al., 2008), and release sites were limited to eucalypt dominated creekline and woodland habitats, where tree hollows were more abundant (H. Bannister \& K. Moseby, pers. obs.). Mean annual rainfall at the release area was $440 \mathrm{~mm}$ (Station 19070, Bureau of Meteorology, 2017).

In the 6 months prior to the reintroduction, 24 remote cameras were deployed across an area of $47 \mathrm{~km}^{2}$ within the National Park, encompassing more than half of the release areas. Averaged camera trap detection levels were $0.02 \%$ for foxes (detected by one camera), $0.8 \%$ for feral cats (detected by $75 \%$ of cameras) and $4.2 \%$ for dingoes (detected by $58 \%$ of cameras; DEWNR and Ecological Horizons, unpubl. data). All three predators are known to influence possum populations (Kerle et al., 1992) and are subject to regular control within the Park. Importantly, foxes are only detected a handful of times each year (Natural Resources SA Arid Lands, 2012). 


\section{Methods}

\section{The reintroduction}

Seventy-nine brushtail possums were translocated from Yookamurra Wildlife Sanctuary to the Ikara-Flinders Ranges National Park in June 2015. Possums were captured either in cage traps, nest boxes or with nets (authors, unpubl. data). Prior to their translocation, all possums underwent health checks under anaesthetic. Morphometric measurements (body mass and head, pes and testes length) and reproductive condition were assessed, and possums were given a unique microchip and ear tag. Forty-eight possums had VHF radio-collars fitted $\left(\mathrm{V}_{5} \mathrm{C}-161 \mathrm{E}, 35 \mathrm{~g}\right.$ or V5C-162E, 41 g, Sirtrack, New Zealand), with mortality sensors that would activate after $10 \mathrm{~h}$ of inactivity. Female possums either had small pouch young or vacant pouches. Of the 48 collared possums ( $24 \mathrm{~F}, 24 \mathrm{M}$ ), two females and five males were subadults; the remainder were adults. Possums were transported inside soft bags inside wooden boxes, or loose inside nest boxes. The vehicle journey took $6 \mathrm{~h}$ and possums were released $<24 \mathrm{~h}$ after capture.

Sixteen radio-collared possums (eight male, eight female) were released in each of three release treatments. These involved either supplementary food (kangaroo pellets, apple, dates, peanut butter and rolled oats), shelter and containment within a fenced pen ('delayed release'), supplementary food and shelter without containment ('nest-box release') or no post-release support ('immediate release'). All possums were released in randomly assigned pairs (one male and one female) and all releases occurred after dark. Releases of collared possums occurred over 2 nights.

\section{Delayed release}

Delayed release pens measured $10 \times 10 \mathrm{~m}$, with a fence height of $1.8 \mathrm{~m}$. A $90 \mathrm{~cm}$ strip of thick plastic fixed to the inside of the fence on the upper half was designed to prevent possums from climbing out and a floppy top prevented other animals entering (Moseby \& Read, 2006). Each pen contained a large tree (some with natural hollows) and two nest boxes hung c. $3 \mathrm{~m}$ above the ground, as well as hollow logs and/or a wood pile. Supplementary food and water was provided ad libitum, presented in a planter box fixed to a tree, in a pet food dish on the ground (monitored via remote camera, Reconyx HC6oo Hyperfire) and scattered throughout the pen; some natural food (E. camaldulensis and/or C. glaucophylla) was also available. Food was replaced late in the day. Pen gates were opened after 11 nights and remote cameras were positioned so that they recorded animals entering or exiting pens. Food continued to be provided inside pens daily for another 10 days, then every 2-3 days for another week.

\section{Nest-box release}

Prior to the release, empty nest boxes $(28 \times 28 \mathrm{~cm}$ base, $41 \mathrm{~cm}$ (front) to $46 \mathrm{~cm}$ (back) height, entrance diameter $11 \mathrm{~cm}$ ) were hung 50-100 $\mathrm{m}$ apart in creeklines and adjacent areas, creating three separate nest-box release areas of 8502,050 m length, and nest boxes containing possums were hung within these areas (Fig. 1). All nest boxes were hung at a height of c. $3 \mathrm{~m}$. Two nest boxes containing possums (one possum per box) were hung on adjacent trees at each release location. Possums released in nest boxes were either animals that were already using nest boxes at the source site $(n=7)$, where 50 nest boxes had been installed 7 months prior to the translocation, or were captured and placed in nest boxes prior to translocation $(n=9)$ because an insufficient number of possums were using nest boxes at the source location. Supplementary food was provided on top of all nest boxes for the same duration of time that food was provided to delayed release possums. As many nest-box release possums dispersed outside nest-box release areas, they were left a small amount of food either at the base of their shelter tree or c. $30 \mathrm{~cm}$ into the entrance of their shelter site, if accessible, when radio-tracked. This occurred approximately every 4 days, during the time when delayed release possums were receiving supplementary food daily. Remote cameras were used to monitor the use of five randomly selected nest boxes for up to 2 months.

\section{Immediate release}

Immediate release possums were released in pairs at the base of two adjacent hollow-bearing eucalypts. They did not have access to supplementary food or shelter.

\section{Monitoring}

Radio-collar signals were checked every 1-3 days for the duration of the study and mortalities were investigated immediately upon discovery. Possums were radio-tracked to their diurnal shelter site weekly (at minimum), with few exceptions. Each shelter site was given a safety score of 1-3, where 1 was accessible to mammalian predators (at ground level and easily visible to the observer) and 3 was considered safe (a tree hollow well above the ground), similar to May et al. (2016). Moderately safe shelter sites given a safety score of 2 were typically hollow logs, rabbit warrens or rock crevices, where possums could have been accessed by a predator but with difficulty. Treadle-operated cage traps were set for radio-collared possums at their shelter sites approximately 10 (range 9-11), 20 (range 18-22), 32 (range 29-35), 60 (range 57-63) and 86 (range 78-94) days posttranslocation using standard cage-trapping procedures (Petit \& Waudby, 2012). Body mass was measured using 
$2 \mathrm{~kg}$ (accuracy $\pm 0.02 \mathrm{~kg})$ or $5 \mathrm{~kg}( \pm 0.025)$ spring scales and the reproductive status of females was assessed by recording the size of any pouch young, teat condition and pouch staining. Intensive monitoring and post-release comparisons are reported for a 3-month period. We considered that differences after this initial period were unlikely to be related to release methods.

\section{Data analysis}

Distance from release site was compared over 12 consecutive weeks from release using a generalised additive mixed model (GAMM) with a temporal correlation structure and an identity link. For delayed release possums, release time was when pens were opened. Release treatment was a fixed effect and repeated measures on individual possums were accounted for as a random effect. Distances were logtransformed to meet the model assumptions of normality and constant variance, and we added one to each distance to retain data for individuals that were sheltering at their release site (distance $=0 \mathrm{~m}$ ). The final dispersal distance of possums once settled (week 6) was compared between treatment groups.

To determine post-release changes in body mass, the difference between mass at release and at the time of recapture was calculated and divided by the release mass, then multiplied by -1 , to give a proportional change in body mass. Negative values indicated mass loss and positive values indicated mass gain. Body mass was adjusted for radio-collars and pouch young mass, using approximate values from Gemmell \& Hendrikz (1993). Delayed release possums were still in pens when captured and weighed at day 10. A linear mixed effects model (LME) was used to test for differences in change in mass between treatment groups, with treatment, sex and time as fixed effects and individual as a random effect.

Shelter site safety scores were converted to binary values, where a score of 3 was safe and 1 or 2 was unsafe as possums were accessible to predators. Time period $1\left(\mathrm{~T}_{1}\right)$ was the first 10 days after release for immediate and nest-box release possums, and the first 10 days after pens were opened for delayed release possums. A binomial generalised linear mixed-effects model (GLMM) with a logit link was used to analyse the effect of treatment and time on the proportion of safe shelter sites used per time period $(\mathrm{T} 1-\mathrm{T} 9)$, with individual included as a random effect.

All analyses were carried out using $R$ (R Core Team, 2016). GAMMs and LMEs were constructed with the package $m g c v$ (Wood, 2011) and model selection statistics were calculated with MuMIn (Barton, 2016). GLMMs were constructed with lme4 (Bates et al., 2016). Statistical significance was assessed using Wald tests with the package car (Fox et al., 2016). Contrasts were calculated using least-squares means with the package lsmeans and summary statistics were calculated using doBy (Højsgaard, 2016).

\section{Results}

\section{Survival and shelter site safety}

During the initial post-release period many possums chose unsafe, exposed diurnal shelter sites (Fig. 2). Despite this, there was no difference in survival between treatment groups. One immediate release female died during the study period, 77 days after release. The cause of death remains unknown despite a post-mortem and testing for predator DNA. The deaths of two other possums during the study period were related to collar design (Moseby \& Bannister, 2016). The proportion of unsafe shelter sites used by possums changed significantly over time $\left(\chi^{2}=13.81, \mathrm{df}=4, \mathrm{P}=0.0079\right.$; Fig. 2$)$, but did not vary between release treatments $\left(\chi^{2}=0.14, \mathrm{df}=2, \mathrm{P}=0.93\right)$ or with treatment over time $\left(\chi^{2}=6.69, \mathrm{df}=8, \mathrm{P}=0.57\right)$. Of nine observation periods ( $\mathrm{T}_{1}-\mathrm{T}_{9}, 10$ days each), four $\left(\mathrm{T}_{4}\right.$, $\mathrm{T}_{6}, \mathrm{~T}_{7}$ and $\mathrm{T} 8$ ) were removed from the analysis because a lack of variance within treatments prevented model convergence. Plotting these values suggested this would not significantly affect the results, as safety scores had almost stabilised by $\mathrm{T}_{3}$. Contrasts of least-squares means revealed no significant difference in safety scores between $\mathrm{T}_{1}$ and $\mathrm{T}_{2}(z=1.2$, $\mathrm{P}=0.55)$, and a trend towards a difference between $\mathrm{T} 1$ and $\mathrm{T}_{3}(z=2.4, \mathrm{P}=0.056)$, and $\mathrm{T} 1$ was significantly different from all subsequent time periods ( $\mathrm{T}_{1}: \mathrm{T}_{5} z=3.1, \mathrm{P}=0.0074$, $\left.\mathrm{T}_{1}: \mathrm{T}_{9} z=2.7, \mathrm{P}=0.028\right)$. Possums were therefore significantly more likely to use unsafe shelter in the first 20 days after release compared to subsequent times. The use of unsafe shelters after T2 was mostly a small number of individuals that showed a preference for hollow logs rather than tree hollows.

\section{Post-release dispersal}

Immediate release possums settled quickly, within the first week after release $(F=1.30$, edf $=1.0, \mathrm{P}=0.26)$, whereas delayed and nest-box release possums took significantly longer

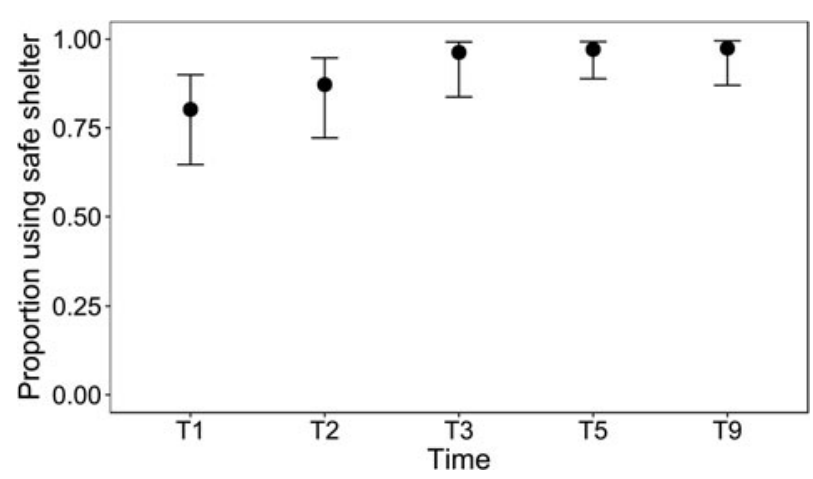

FIG. 2 The proportion of possums using safe shelter sites at various times after release, with $95 \%$ confidence intervals. The interval between each time period was 10 days. 
(nest-box release $F=5.18$, edf $=2.38, \mathrm{P}=0.0026$; delayed release $F=23.62$, edf $=7.65, \mathrm{P}=<0.0001$; Fig. 3). However, there was no difference in the overall dispersal distance between treatment groups (Table 1). Six weeks after release, when possums in all treatments had settled, dispersal distances were $0.08-17.02 \mathrm{~km}$, with a mean distance from release site of $1.03 \mathrm{~km}$ (range $0.09-4.09 \mathrm{~km}$ ) for immediate release, $2.68 \mathrm{~km}(0.11-17.02 \mathrm{~km})$ for nest-box release and $1.49 \mathrm{~km}(0.08-4.88 \mathrm{~km})$ for delayed release possums. Seven out of 44 radio-collared possums in the study (16\%) hyperdispersed, travelling more than three times the mean range length reported in previous arid/semi-arid studies (mean $=0.88 \mathrm{~km}$; Foulkes, 2001; Short \& Hide, 2014) before settling (Supplementary Table 2). Release treatment had no influence on hyperdispersal $\left(\chi^{2}=1.19, \mathrm{df}=2, \mathrm{P}=0.55\right)$. Encouragingly, $61 \%$ of possums remained within $1 \mathrm{~km}$ of their release site 6 weeks after release.

\section{Body mass}

At the time of translocation, the mean body mass of radiocollared possums was $1,577 \pm \mathrm{SE} 38 \mathrm{~g}$ and did not significantly differ between sexes (Wilcoxon rank sum test, $W=292$, $\mathrm{P}=0.94$ ) or treatment groups (Kruskal-Wallis rank sum test, $\chi^{2}=5.06, \mathrm{df}=2, \mathrm{P}=0.08$ ). The mass of translocated possums changed significantly over the post-release monitoring period $\left(\chi^{2}=162.42, \mathrm{df}=1, \mathrm{P}=<0.0001\right)$, but there was no difference between treatment groups $\left(\chi^{2}=0.14\right.$, $\mathrm{df}=2, \mathrm{P}=0.93)$ and no significant interaction between treatment and time $\left(\chi^{2}=0.06, \mathrm{df}=2, \mathrm{P}=0.97\right.$; Fig. 4). Most $(83 \%)$ of the possums in delayed release pens lost mass after release. Approximately half of all possums (44, 45 and $56 \%$ of nest-box, delayed and immediate release recaptures respectively) had lost more than $10 \%$ body mass 10 days after release, and 20 days after translocation $82 \%(\mathrm{n}=39)$ of recaptured possums had lost mass.

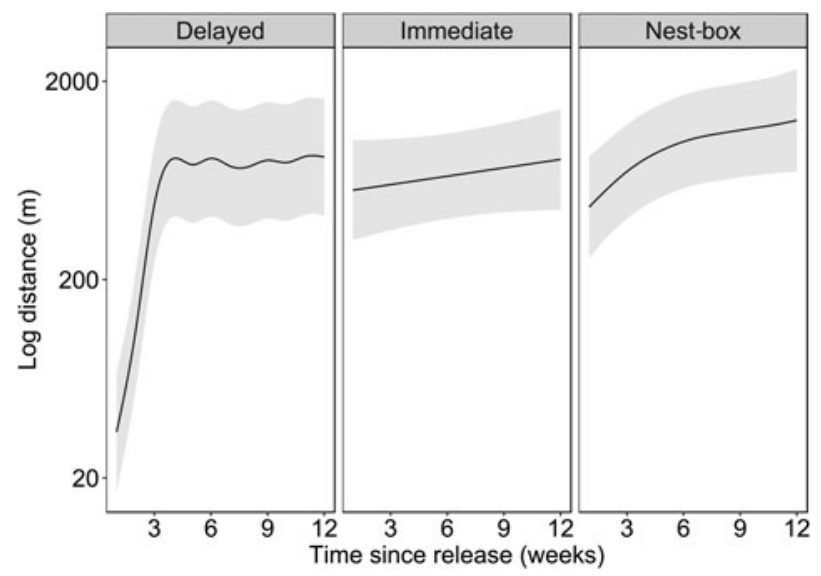

FIG. 3 Estimated distance from release site for possums in three release treatments over time, with $95 \%$ confidence intervals (shaded). Delayed release time zero was when release pens were opened.
TABLE 1 Generalised additive mixed model coefficients contrasting the mean dispersal distance of possums by treatment group, 6 weeks after release.

\begin{tabular}{llll}
\hline Contrast & SE & $t$ & $\mathrm{P}$ \\
\hline Immediate vs nest-box & 0.36 & 0.83 & 0.41 \\
Immediate vs delayed & 0.39 & 0.82 & 0.41 \\
Nest-box vs delayed & 0.39 & 1.58 & 0.12 \\
\hline
\end{tabular}

However, 60 days after release, most possums $(82 \%, n=17)$ in all treatments were heavier than their translocation mass. Males gained mass at a faster rate than females $\left(\chi^{2}=11.67\right.$, $\mathrm{df}=1, \mathrm{P}=0.00063$; Fig. 4). As a result of differences in trap success for individuals, not every possum was successfully captured for each sampling period.

\section{Reproduction}

Release method did not influence female reproduction. Seventy-five, 100 and $63 \%$ of radio-collared females (immediate, nest-box and delayed release respectively) had pouch young prior to translocation and all were retained postrelease. Additionally, females from each of the release treatments gave birth during the 3-month study period (at least four delayed release females, one uncollared immediate release female and one nest-box release female). Only three radio-collared females (two immediate release and one delayed release) did not have pouch young at any time during the study.

\section{Release techniques}

Four males escaped delayed release pens (on nights one $(\mathrm{n}=1)$, three $(\mathrm{n}=2)$ and four $(\mathrm{n}=1))$ and were not included in subsequent analyses. The first day post-release, only one

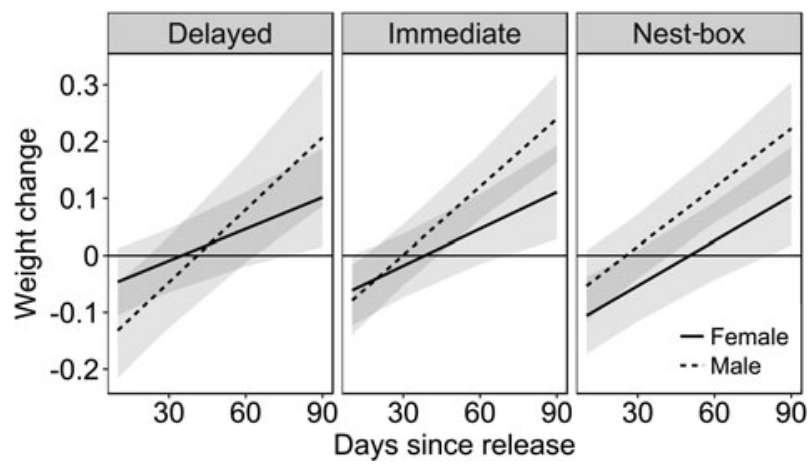

FIG. 4 Estimated proportional change in body mass, with shaded $95 \%$ confidence intervals, over five sampling periods (day 10, 20, 32,60 and 86) for translocated brushtail possums, starting at day 10 , for three release treatment groups. Mass change at time o (translocation) was zero. The first sampling period for delayed release possums (day 10) was when they were still contained in release pens. 
delayed release possum was sheltering in a safe location, in a nest box. The remainder sheltered in more vulnerable locations: in hollow logs, under wood piles, in the open or at the top of a tree. In pens where natural hollows were present, possums took two $(n=5)$ or three $(n=3)$ nights to use a tree hollow, with an eighth possum never using available tree hollows. Where nest boxes were the only above ground shelter available, only one of three possums used one. Within pens, possums mostly sheltered in hollow logs/ woodpiles (49\%) or tree hollows (35\%), occasionally using a nest box $(9 \%)$ or sheltering in the open $(7 \%)$. Shelter sites were not dominated by larger animals or one particular sex, and possums were recorded sharing shelter on $47 \%$ of occasions where two animals remained in a pen. When contained in pens possums ate some of the supplementary food provided, but once pens were opened most used them for shelter rather than a food source, venturing outside the pen at night. Five of 12 possums left their pen on the first night it was open; the remainder took 2-9 nights (mean $=3$ nights). Half of the possums used diurnal shelter sites inside the pen for up to 18 days (mean $=7$ days) after the pens were opened, whereas two others sheltered outside the pen but returned for up to 10 days after supplementary food ceased to be provided. In nest-box release areas, possums were detected a total of six times at three of the five nest boxes that were monitored by remote camera over 2 months after release (256 camera trap nights, $2.3 \%$ trap success), eating supplementary food but not using the boxes as shelter. No radio-collared possums from any treatment were found using nest boxes in nest-box release areas after the first night post-release.

\section{Discussion}

Supportive release methods, including delayed release pens and nest-box release areas with supplementary food, did not provide tangible benefits to translocated brushtail possums at our study site. There was no difference in the survival, reproduction, change in mass, or dispersal distance of possums between release treatments, but immediate release possums settled fastest. The control of introduced predators, especially foxes, probably contributed to the high survival of possums; we recorded no predation within the first 3 months, in contrast to translocations at three other unfenced sites where 42,74 and $15 \%$ of released possums were killed by introduced predators (foxes/feral cats) shortly after release (Pietsch, 1995; DEC, 2012; May et al., 2016). The mitigation of threatening processes, particularly introduced predators, is considered a key factor in many successful reintroductions (Brambell, 1977; Bellingham et al., 2010; Moseby et al., 2011), and our results support this.

Although nest boxes are readily used by brushtail possums in areas where natural hollows are limited (Harper et al., 2005; Lindenmayer et al., 2015), they were not used by possums in our study, suggesting natural shelter sites were plentiful. Further to the current study, no radiocollared possums were found to use nest boxes as shelter in the 22-month period after release (authors, unpubl. data). Use of nest boxes may be influenced by nest-box height, orientation, dimensions, entrance size, temperature or low encounter rates, or simply a preference for natural hollows (Isaac et al., 2008; Goldingay, 2015; Le Roux et al., 2016). The use of ground-level shelters such as hollow logs and woodpiles inside release pens instead of nest boxes suggests that nest-box design, placement or accessibility may have influenced use. Despite the presence of natural hollows as well as nest boxes (in some areas), many possums chose unsafe, exposed shelter during the initial post-release period, gradually improving shelter choice over time. Similar behaviour has been observed for other possum translocations (Pietsch, 1995; Short \& Hide, 2014). We suggest that had predator numbers been higher or foxes been present we may have observed a high mortality rate during this acclimation phase. In that situation, easily accessible supplementary shelters may have been beneficial, yet possums in nest-box release areas did not use nest boxes for shelter, and in contrast to our hypothesis, possums released in nest boxes did not subsequently return to them.

Haylock (2008) found that possums captured from in situ nest boxes made long distance movements upon release and did not return, even when the nest box was known to be a preferred shelter site previously. Possums in our study may have responded similarly. Despite the availability of suitable shelter, some possums still required an acclimation period in their new environment before sheltering safely. Because of this, predator management should be concentrated in the time preceding and immediately following a possum translocation, and future translocations should consider the predation risks associated with this settlement phase.

Supplementary feeding did not influence body mass in possums, nor did it reduce dispersal distance. Similarly, supplementary feeding had no effect on the post-release mass of translocated mala Lagorchestes hirsutus or eastern bettongs Bettongia gaimardi (Hardman \& Moro, 2006; Batson et al., 2015). The combination of initial mass loss and poor shelter site choice by possums suggests that supplementary food and shelter could be beneficial immediately after release, particularly if predators are present, but neither were effective in our study: the available supplementary shelter was not used, supplementary food was rarely consumed when alternatives were available, and it did not prevent loss of mass. The appeal or efficacy of these supportive measures must be improved for them to be of benefit to reintroduced animals in environments where post-release predation risk is high. In our study, temporary containment and supplementary food provided no discernible benefits for translocated possums, and immediate release possums settled the 
fastest. For this reason, combined with low post-release predation risk, an immediate release was the most suitable reintroduction method for possums in the Ikara-Flinders Ranges National Park.

The absence of existing possum populations at release sites may have contributed to translocation success, as releasing possums into areas with an existing population has previously been linked to hyperdispersal and translocation failure (Pietsch, 1995; Clinchy, 1999). Immediate and nestbox release possums had an opportunity to disperse and settle earlier than delayed release possums (initially contained in pens), so it is possible that uncollared animals had dispersed to areas surrounding pens in this time. However, intensive, regular trapping combined with having a large proportion of the population radio-collared suggests this was unlikely. An absence of possums in the wider reintroduction area could, in contrast, have contributed to the delay in possums using suitable natural hollows. While possums are not highly social, they have overlapping home ranges and different possums sometimes use the same shelter site at the same or different times (Cruz et al., 2012; H. Bannister, pers. obs.). The scent of conspecifics may encourage possums to use suitable shelters sooner, or to settle into a new area without feeling isolated, but this has not yet been explored. To date, the influence of resident possums on translocation success has not been experimentally tested.

Stress is an unavoidable component of translocations and although not monitored in our study, may have contributed to post-release mass loss or hyperdispersal (Moberg, 2000; Dickens et al., 2010). Stress has been identified as a concern for captive possums (Presidente, 1984; Baker \& Gemmell, 1999). However, immediate and nest-box release possums lost mass along with delayed release possums, suggesting that if stress was a factor then it affected the mass of all treatment groups equally. Radio collars may have also initially caused possums to become stressed. Along with stress, mass loss probably resulted from possums having to locate new food and shelter sources or adapting their diet to their new environment. Because mass was regained relatively rapidly (and subsequently increased), mass loss and possibly stress ultimately did not affect the reintroduction outcome.

In environments where post-release predation risk is high, the use of risky shelters and post-release mass loss may necessitate the provision of supplementary food and shelter. Delayed release experiments typically follow similar formats and reintroduction biology has not yet explored novel ways of increasing the appeal and subsequent use of supplementary items. Future reintroductions could trial various ways of presenting post-release support, with the potential to improve reintroduction success. Encounter rates with nest boxes and natural hollows shortly after release could be improved by conducting an experiment in which a fence is erected around the base of a hollow-bearing tree prior to the release of a possum, removing it once it had climbed the tree, or after just one night, preventing possums from immediately moving off along the ground and sheltering in unsafe locations. This method would not involve containing the possums for several days as occurred with the delayed release, but would be labour intensive. Additionally, the influence of the scent or presence of conspecifics could be investigated. Nutritious, native supplementary food may have had a positive effect on mass compared to the non-native and sometimes processed supplementary food we provided. Improving the appeal and effectiveness of supplementary items should continue to be an aspect of research on reintroduction biology.

The relatively slow adaptability of possums to a new environment observed in the current study and in previous translocations (Pietsch, 1995; Short \& Hide, 2014) needs to be accounted for if future reintroductions are undertaken. An assessment of the adaptability of a species to new conditions as well as their post-release behaviour should be used to inform release methods for reintroductions of any species. Our results demonstrate that translocation projects should not assume post-release support is required or has a positive effect on translocation success, and we advocate only using such measures with an experimental approach. In our study, brushtail possums were most suited to an immediate release because natural food and shelter sites were plentiful and post-release predation risk was low. The challenge for future reintroductions will be to identify suitable methods to encourage released animals to use supportive measures effectively, in situations where they are required.

\section{Acknowledgements}

The reintroduction of brushtail possums to the Ikara-Flinders Ranges National Park occurred through a partnership between the South Australian Department of Environment, Water and Natural Resources and funding partner the Foundation for Australia's Most Endangered Species, with the Australian Wildlife Conservancy providing possums for translocation and assisting with the source population assessment. Additional funding was provided by the Holsworth Wildlife Research Endowment, Nature Foundation South Australia, Biology Society of South Australia and The University of Adelaide. Thanks to Patrick Hodgens, Tali Moyle, Trish Mooney, Kiarrah Smith, Kimberly McCallum, Amanda McLean, Cassandra Holt and Australian Wildlife Conservancy staff (particularly Noel Riessen, Melissa Farrelly, David Roshier and Keith Bellchambers) for various assistance. Two anonymous reviewers provided useful comments. Research was conducted according to the Australian Code for the Care and Use of Animals for Scientific Purposes (2013), with ethics approvals from the South Australian Wildlife Ethics Committee and the University of Adelaide's Animal Ethics Committee.

\section{Author contributions}

Experimental design: HB, KM, RB, DP; data collection: HB, KM, RB; data analysis and preparation of figures: $\mathrm{HB}, \mathrm{SD}$; writing: $\mathrm{HB}$; reviewing and editing: $\mathrm{HB}, \mathrm{KM}, \mathrm{RB}, \mathrm{DP}, \mathrm{SD}$. 


\section{References}

Baker, M.L. \& Gemmell, R.T. (1999) Physiological changes in the brushtail possum (Trichosurus vulpecula) following relocation from Armidale to Brisbane, Australia. Journal of Experimental Zoology, 284, 42-49.

Barton, K. (2016) MuMIn: multi-model inference. Http://CRAN. R-project.org/package $=$ MuMIn [accessed 7 June 2017].

Bates, D.M., Maechler, M., Bolker, B., Walker, S., Christensen, R.H.B., Singmann, H. et al. (2016) lme4: Linear mixed effects models using 'Eigen' and $\mathrm{S}_{4}$. Http://lme4.r-forge. r-project.org [accessed 7 June 2017].

Batson, W.G., Gordon, I.J., Fletcher, D.B. \& Manning, A.D. (2015) The effect of pre-release captivity on post-release performance in reintroduced eastern bettongs Bettongia gaimardi. Oryx, 50, 664-673.

Bellingham, P.J., Towns, D.R., Cameron, E.K., Davis, J.J., Wardle, D.A., Wilmshurst, J.M. \& Mulder, C.P.H. (2010) New Zealand island restoration: seabirds, predators, and the importance of history. New Zealand Journal of Ecology, 34, 115-136.

Brambell, M.R. (1977) Reintroduction. International Zoo Yearbook, $17,112-116$.

Bright, P.W. \& Morris, P.A. (1994) Animal translocation for conservation: performance of dormice in relation to release methods, origin and season. Journal of Applied Ecology, 31, 699-708.

Bureau of Meteorology (2017) Climate data online: daily rainfall. Http://www.bom.gov.au/climate/data/index.shtml [accessed 27 March 2017].

Burrows, N.D. \& Christensen, P.E.S. (2002) Long-term trends in native mammal capture rates in a jarrah forest in south-western Australia. Australian Forestry, 65, 211-219.

Clinchy, M. (1999) Does Immigration 'Rescue' Populations from Extinction? PhD thesis. The University of British Colombia, Vancouver, Canada.

Cruz, J., Sutherland, D.R. \& Leung, L.K.P. (2012) Den use, home range and territoriality of the koomal (Trichosurus vulpecula hypoleucus) with implications for current forest management strategies. Australian Journal of Zoology, 60, 141-151.

DEC (2012) Gorgon Gas Development: Threatened and Priority Species Translocation and Reintroduction Program. Annual report 2011/12. Department of Environment and Conservation, Perth, Australia.

Dickens, M.J., Delehanty, D.J. \& Romero, L.M. (2010) Stress: an inevitable component of animal translocation. Biological Conservation, 143, 1329-1341.

Fischer, J. \& Lindenmayer, D.B. (2000) An assessment of the published results of animal relocations. Biological Conservation, 96, 1-11.

Foulkes, J.N. (2001) The ecology and management of the common brushtail possum Trichosurus vulpecula in central Australia. $\mathrm{PhD}$ thesis. The University of Canberra, Canberra, Australia.

Fox, J., Weisberg, S., Adler, D., Bates, D.M., Baud-Bovy, G., ElLison, S. et al. (2016) car: companion to applied regression. Https://CRAN.R-project.org/package=car [accessed 7 June 2017]

Gemmell, R.T. \& Hendrikz, J.K. (1993) Growth rates of the bandicoot Isoodon macrourus and the brushtail possum Trichosurus vulpecula. Australian Journal of Zoology, 41, 141-149.

Goldingay, R.L. (2015) Temperature variation in nest boxes in eastern Australia. Australian Mammalogy, 37, 225-233.

Hardman, B. \& Moro, D. (2006) Optimising reintroduction success by delayed dispersal: is the release protocol important for hare-wallabies? Biological Conservation, 128, 403-411.

Harper, M.J., McCarthy, M.A. \& van der Ree, R. (2005) The use of nest boxes in urban natural vegetation remnants by vertebrate fauna. Wildlife Research, 32, 509-516.
Haylock, K. (2008) Habitat use of brushtail possums, Trichosurus vulpecula, in revegetated areas of Monarto Woodlands, South Australia. Honours thesis. The University of Adelaide, Adelaide, Australia.

HøJSGAARD, S. (2016) doBy: groupwise statistics, LSmeans, linear contrasts, utilities. Https://CRAN.R-project.org/package=doBy [accessed 7 June 2017].

How, R.A. \& Hillcox, S.J. (2000) Brushtail possum, Trichosurus vulpecula, populations in south-western Australia: demography, diet and conservation status. Wildlife Research, 27, 81-89.

IsaAC, J.L., De Gabriel, J.L. \& Goodman, B.A. (2008) Microclimate of daytime den sites in a tropical possum: implications for the conservation of tropical arboreal marsupials. Animal Conservation, $11,281-287$.

Kerle, J.A. (1984) Variation in the ecology of Trichosurus: its adaptive significance. In Possums and Gliders (eds A.P. Smith \& I.D. Hume), pp. 115-128. Surrey Beatty \& Sons, Sydney, Australia.

Kerle, J.A. (2001) Possums: the brushtails, ringtails and greater glider. In Australian Natural History Series (ed. T.J. Dawson), pp. 1-128. UNSW Press, Sydney, Australia.

Kerle, J.A., Foulkes, J.N., Kimber, R.G. \& Papenfus, D. (1992) Decline of the brushtail possum, Trichosurus vulpecula (Kerr 1798), in arid Australia. The Rangeland Journal, 14, 107-127.

Kerle, J.A., McKay, G.M. \& Sharman, G.B. (1991) A systematic analysis of the brushtail possum Trichosurus vulpecula (Kerr, 1972) (Marsupialia: Phalangeridae). Australian Journal of Zoology, 39, 313-331.

Knox, C.D. \& Monks, J.M. (2014) Penning prior to release decreases post-translocation dispersal of jewelled geckos. Animal Conservation, 17, 18-26.

Le Roux, D.S., Ikin, K., Lindenmayer, D.B., Bistricer, G., Manning, A.D. \& Gibbons, P. (2016) Effects of entrance size, tree size and landscape context on nest box occupancy: considerations for management and biodiversity offsets. Forest Ecology and Management, 366, 135-142.

Lindenmayer, D., Crane, M., Blanchard, W., Okada, S. \& Montague-Drake, R. (2015) Do nest boxes in restored woodlands promote the conservation of hollow-dependent fauna? Restoration Ecology, 24, 244-251.

May, T.M., Page, M.J. \& Fleming, P.A. (2016) Predicting survivors: animal temperament and translocation. Behavioral Ecology, 27, 969-977.

Mitchell, A.M., Wellicome, T.I., Brodie, D. \& Cheng, K.M. (2011) Captive-reared burrowing owls show higher site-affinity, survival, and reproductive performance when reintroduced using a soft-release. Biological Conservation, 144, 1382-1391.

Moberg, G.P. (2000) Biological responses to stress: implications for animal welfare. In The Biology of Animal Stress: Basic Principles and Implications for Animal Welfare (eds G.P. Moberg \& J.A. Mench), pp. 1-21. CAB International, Wallingford, UK.

Moseby, K. \& B ANnister, H. (2016) Warning about radio-collar design. Http://us7.campaign-archive2.com/?u=1769923dde6e446129472ad6b\& $\mathrm{id}=43$ ba $54393 \mathrm{f} \& \mathrm{e}=498136 \mathrm{e} 15 \mathrm{~b}$ [accessed 15 January 2017].

Moseby, K.E., Hill, B.M. \& Lavery, T.H. (2014) Tailoring release protocols to individual species and sites: one size does not fit all. PLOS ONE, 9, e99753.

Moseby, K.E. \& Read, J.L. (2006) The efficacy of feral cat, fox and rabbit exclusion fence designs for threatened species protection. Biological Conservation, 127, 429-437.

Moseby, K.E., Read, J.L., Paton, D.C., Copley, P., Hill, B.M. \& Crisp, H.A. (2011) Predation determines the outcome of 10 reintroduction attempts in arid south Australia. Biological Conservation, 144, 2863-2872. 
Natural Resources SA Arid Lands (2012) Bounceback: Celebrating 20 Years. Department of Environment, Water and Natural Resources, Adelaide, Australia.

Petit, S. \& Waudby, H.P. (2012) Standard operating procedures for aluminium box, wire cage, and pitfall trapping, handling, and temporary housing of small wild rodents and marsupials. Australian Journal of Zoology, 60, 392-401.

PietsCh, R.S. (1995) The fate of urban common brushtail possums translocated to schlerophyll forest. In Reintroduction Biology of Australian and New Zealand Fauna (ed. M. Serena), pp. 239-246. Surrey Beatty \& Sons, Chipping Norton, Australia.

Poole, A. \& Lawton, C. (2009) The translocation and post release settlement of red squirrels Sciurus vulgaris to a previously uninhabited woodland. Biodiversity and Conservation, 18 , 3205-3218.

Presidente, P.J.A. (1984) Parasites and diseases of brushtail possums (Trichosurus spp): occurrence and significance. In Possums and Gliders (eds A.P. Smith \& I.D. Hume), pp. 171-19o. Surrey Beatty \& Sons, Sydney, Australia.

R Core Team (2016) $R$ : A language and environment for statistical computing. Http://www.R-project.org [accessed 7 February 2017].

Richardson, K., Castro, I.C., Brunton, D.H. \& Armstrong, D.P. (2015) Not so soft? Delayed release reduces long-term survival in a passerine reintroduction. Oryx, 49, 535-541.

Rickett, J., Dey, C.J., Stothart, J., O’Conner, C.M., Quinn, J.S. \& Weinong, J. (2013) The influence of supplementary feeding on survival, dispersal and competition in translocated brown teal, or Pateke (Anas chlorotis). Emu, 113, 62-68.

Scott, J.M. \& Carpenter, J.W. (1987) Release of captive-reared or translocated endangered birds: what do we need to know? Auk, 104 544-545.
Seddon, P.J., Armstrong, D.P. \& Maloney, R.F. (2007) Developing the science of reintroduction biology. Conservation Biology, 21, 303312 .

Short, J. \& Hide, A. (2014) Successful reintroduction of the brushtail possum to Wadderin Sanctuary in the eastern wheatbelt of western Australia. Australian Mammalogy, 36, 229-241.

Swaisgood, R.R. (2010) The conservation-welfare nexus in reintroduction programmes: a role for sensory ecology. Animal Welfare, 19, 125-137.

Thompson, J.R., Vernon, C.B., Torres, S.G. \& Mulcahy, G.P. (2001) Translocation techniques for mountain sheep: does the method matter? The Southwestern Naturalist, 46, 87-93.

Tunbridge, D. (1991) The Story of the Flinders Ranges Mammals. Kangaroo Press, Kenthurst, Australia.

Wood, S.N. (2011) Fast stable restricted maximum likelihood and marginal likelihood estimation of semiparametric generalized linear models. Journal of the Royal Statistical Society (B), 73, 3-36.

\section{Biographical sketches}

HANNAH BANNISTER's research interests include the ecology of mammals, conservation biology and restoration ecology. RoBERT BRANDLE has worked on threatened species, including reintroduction programmes, as well as documenting flora and fauna communities across South Australia. Steven Delean is an ecological statistician with research interests in modelling spatial and temporal biodiversity responses to ecosystem change. DAVID PATON is an ecologist whose work focuses on conservation and restoration, with a strong commitment to long-term studies. Kat HER IN E Moseb Y's research focuses on the impacts of exotic species, the restoration of native ecosystems and fauna reintroductions. 